\title{
Ficcionalización de Bolivia. La novela/leyenda del siglo diez i nueve 1847-1896. Compilación, estudio, notas y edición de Juan Pablo Soto J., con la colaboración de Máximo Pacheco B. 2 tomos. 2483 páginas. Cochabamba: S/e, 2016.
}

Ficcionalización de Bolivia. La novela/leyenda del siglo diez i nueve 1847-1896 es el fruto de largos años e innumerables horas de investigación en archivos y hemerotecas, y de una cuidadosa labor de edición de 56 novelas, novelas cortas y leyendas. En dos tomos, con unas 2500 páginas, están ahora disponibles tanto los principales "clásicos" de la narrativa de ficción boliviana del siglo XIX como una serie de relatos poco o nada conocidos, incluso entre especialistas. Es una obra monumental, que por su extensión y su rigor académico impulsará la revisión de los estudios literarios y culturales bolivianos del siglo XIX.

Desde su título, alude a la estrecha relación entre ficción y realidad en la época, y a la orientación constructivista, ahora dominante, en los estudios sobre la nación. Participa de la re-conceptualización de los estudios de la nación e interpretaciones que se centran en la formación de las culturas nacionales a través de la escritura y otras manifestaciones culturales. Tal redefinición del "objeto conceptual" de la nación comenzó a tener considerable impacto en las discusiones de las nacionalidades hispanoamericanas hace unas décadas, gracias a la recepción de Imagined Communities. Reflections on the Origin and Spread of Nationalism (1983) [Comunidades imaginadas. Refexiones sobre el origen y la difusión del nacionalismo] de Benedict Anderson y de La ciudad letrada (1984) de Ángel Rama. 
En el campo de la literatura y de los estudios culturales, la colección de ensayos Nation and Narration [Nación y narración] (1990) editada por Homi Bhabha, consolidó el paradigma de Anderson en la vanguardia académica y orientó el estudio de la nación hacia su formación narrativa, particularmente por medio de novelas. Llevó a los investigadores (no sólo a los críticos culturales sino también a algunos historiadores) a preguntarse ya no qué es la nación sino cómo se escribe. Tal aproximación culturalista y discursiva del estudio de la nación es también apoyada por prominentes historiadores materialistas, como E. J. Hobsbawm, quien en Nations and Nationalism since 1780 (1992) [Naciones y nacionalismo desde 1780] señala que, para aproximarse a la cuestión nacional, "es más productivo empezar con el concepto de 'la nación' (i.e. con 'el nacionalismo') que con la realidad que representa” (9). Un año después de la publicación del libro de Bhabha, Doris Sommer publica Foundational Fictions: The National Romances of Latin America (1991) [Ficciones fundacionales, los romances nacionales de América Latina], obra que muestra lo inseparable que son "la política y la ficción en la historia de la construcción de la nación", y más específicamente, las novelas románticas y la historia patriótica (Foundational Fictions 5-7). Desde entonces, la bibliografía sobre el tema sigue creciendo, y si bien se pueden cuestionar algunos aspectos de estos enfoques, siguen siendo útiles para analizar cómo las culturas letradas imaginan la nación en su periodo formativo temprano.

Ficcionalización de Bolivia documenta, precisamente, cómo un medio centenar de relatos imaginan el país, su sociedad, su historia, sus costumbres y sus sueños. Nos remonta a cómo se veían estos temas en la segunda mitad del siglo XIX. Al usar la "i" latina en el título, como con guiño a los lectores, la obra nos remite a la errática ortografía de los libros y periódicos de la época, a su impronta textualista y documental, y a los frutos de la gran labor de investigación que despliega. Similarmente, el modo inicial de publicación de Ficcionalización, mediante una impresión personal, financiada mediante una especie de "subscripción", también nos refiere a modos de producción y circulación decimonónicos de libros y periódicos.

Ficcionalización incluye una importante introducción de Juan Pablo Soto y la edición anotada de 56 obras narrativas de ficción, sean novelas o leyendas, que se publicaron entre 1847 y 1897 . Adicionalmente, en el tomo I (1165-1191) se incluye una obra anónima, Las culpas de los padres. Mis observaciones a continuación se basan en las primeras 56 obras. 
En su gran mayoría, estas obras salen primero serialmente (por entregas o como folletines), en revistas y periódicos de las principales ciudades del país (La Paz, Chuquisaca, Tarija, Potosí, Cochabamba y Santa Cruz) o de capitales de países vecinos (Buenos Aires, Santiago y Lima). Concretamente, entre las 56 novelas/leyendas, se incluye una obra previamente inédita (Borradores de una novela histórica, de José Ballivián) y 15 que salen únicamente en forma de folleto o libro (y no por medios periodísticos). En la publicación de las otras 40 obras (más de $70 \%$ del total), la prensa tiene un papel protagónico. De estas cuatro decenas, 20 obras salieron por entregas o como folletines, en las páginas de distintos periódicos o revistas, en secciones diversamente llamadas folletín, variedades, literatura o varios (y seguramente nunca fueron re-editadas en forma de libro); 16 se distribuyen primero por entregas, como folletines, y luego se editan como libros o folletos; y 4 siguen el proceso inverso de publicación: primero fueron publicadas como folleto, y posteriormente se vuelven a imprimir como folletín, ya sea al finalizar la publicación del libro o algunos años después.

La publicación de novelas/leyendas, como la de los periódicos, crece en las últimas décadas. Las primeras 28 obras se publican entre 1847 y 1878 (poco más de tres décadas); las siguientes 28 entre 1880 y 1897 (menos de 20 años). El primer grupo sólo incluye 3 obras que salen únicamente como folletos (las otras 25, aparecen como folletines, en la prensa). El número de obras publicadas como folletos sube a 12 en el segundo grupo, reflejando una mayor diversidad de medios de publicación a fines de siglo, sin que esto signifique el abandono de los periódicos. En este sentido, cabe recordar que las imprentas y periódicos consideraban estas obras de ficción como un atractivo para un creciente público lector, particularmente el femenino; y como una manera de aumentar el número de subscriptores. Hacia fines de siglo, los periódicos regalaban los folletos como "primas" o premios anuales a sus leales subscriptores. También se observa que en las últimas décadas del siglo se publican relatos más largos que en las anteriores (Juan de la Rosa [1885] es la obra más extensa, y la primera del segundo tomo). Se publican, entonces, novelas más largas junto a leyendas cortas y otras formas narrativas, como los tradicionales cuadros de costumbres y las nuevas crónicas periodísticas. Los poemas siguen siendo populares, y también se siguen publicando obras dramáticas. En otras palabras, se acelera la institucionalización de la literatura nacional a fines del siglo XIX. 
Al discutir decenas de obras previamente desconocidas por la crítica, no debe sorprender que la "Introducción" de Juan Pablo Soto se constituya en uno de los más importantes estudios generales sobre la narrativa boliviana del siglo XIX. Contextualiza los relatos que se incluyen en estos dos volúmenes, y corrige o rectifica muchas de las afirmaciones de las historias de la novela o de la literatura boliviana, muchas de ellas caracterizadas por la simple repetición de los datos, incluyendo los errores, de otras anteriores. Soto documenta siempre sus afirmaciones basándose en un conocimiento directo y profundo de los documentos originales y de estudios sobre el tema. En este sentido, sigue al pie de la letra la recomendación que hacía Charles Arnade a los investigadores (y que se incluye como especie de epígrafe a Ficcionalización): consultar fuentes primarias en los "espléndidos archivos bolivianos." Destaca, también, los principales temas y estilos de las distintas obras editadas, observando la significativa impronta del romanticismo en muchos textos, y los momentos históricos que privilegian (los "orígenes" patrios o la época de la independencia, sobre todo). Finalmente, observa el carácter elitista de la cultura letrada de la época, compartido por los distintos relatos. Se imagina y se escribe la nación, se "ficcionaliza Bolivia," pero se lo hace desde la perspectiva de las clases letradas, con todas las limitaciones que esto implica.

Cada una de las novelas/leyendas trae una nota biográfica sobre el autor y detalles sobre la publicación de la obra (y de sus distintas ediciones, en el caso de las relativamente pocas obras que fueron re-editadas). En el caso de los folletines, Soto apunta los distintos periódicos, números y fechas en los que salieron, y en ocasiones destaca que las obras permanecen incompletas debido a que faltan números en muchas colecciones de los periódicos. También se incluyen algunos prólogos o ensayos introductorios, publicados originalmente con las obras, o en una de sus primeras re-ediciones, como en el caso del importante prólogoensayo de Gabriel René Moreno a La isla (La Aurora Literaria, Sucre, 186364) de Manuel María Caballero, en la segunda edición, de Moreno, publicada en la Revista Chilena, en 1878. Estos importantes textos programáticos definen lo que Soto llama una "teoría de la novela" en su "Introducción," o una poética de la narrativa boliviana y latinoamericana, de crucial importancia para entender cómo se leían estas obras en la época en que fueron publicadas. Articulan el "horizonte de expectativas" o las convenciones culturales con las que se aproximan autores y lectores a los 
textos en una época determinada. Funcionan como guías de lectura para la audiencia de las obras específicas y otras semejantes. Al leer estas "poéticas" u obras particulares se aprenden estrategias que enmarcan la comprensión de los textos y se adquieren ciertas competencias interpretativas que facilitan la lectura de otras obras que comparten convenciones similares. Sin entrar en detalles, se puede señalar que en varios de estos textos se aboga por el carácter nacional de la literatura y se la inserta dentro de los modelos culturales letrados del liberalismo, con su fe en el progreso; sobre todo, se recomienda que novelas y leyendas describan la naturaleza, la sociedad, las costumbres, y la historia nacionales. En otras palabras, que se ficcionalice a Bolivia.

Las ediciones incluyen, también, más de mil notas eruditas que esclarecen la lectura del texto y, en el caso de las dos ediciones tempranas de La Isla, explican sus variantes textuales. Las notas de referencia, algunas de ellas tomadas del Diccionario histórico de Bolivia (dirigido por Josep Barnadas), proporcionan información enciclopédica sobre los personajes citados en los relatos, sobre toponímicos o lugares geográficos, y un glosario de bolivianismos, que explican el significado de plantas o animales regionales. También aclaran datos históricos y acontecimientos poco conocidos en su época y menos todavía hoy en día. No resulta exagerado señalar que hojear estas notas de referencia es como consultar una enciclopedia con detalles del imaginario letrado de los autores del siglo XIX y sus obras; imaginario que, si bien sigue dominado por autores clásicos y pensadores europeos modernos, también muestra que al mismo tiempo se piensa, cada vez más, en el propio país.

La inextricable relación de la literatura decimonónica con la prensa, aspecto ignorado, mencionado de paso o como algo meramente anecdótico en la gran mayoría de las historias literarias de la época, es en realidad un aspecto central a su naturaleza misma, más allá de ser los periódicos el principal medio de publicación. Dada la detallada documentación de estos datos por Soto, tomar en cuenta el papel de la prensa en el caso de la narrativa boliviana será aún más urgente a partir de Ficcionalización. Paradójicamente, si en el siglo XIX publicar un relato en la prensa como folletín o por entregas garantizaba una difusión relativamente amplia, el mismo fenómeno ha condenado a muchas de estas obras a permanecer inéditas o conocidas por muy pocos investigadores, que "se queman las pestañas" leyéndolas en las páginas de distintas gacetas o como folletos empolvados en los archivos. Soto acierta 
plenamente al afirmar que con contadas excepciones (Juan de la Rosa, las obras de Lindaura Anzoátegui de Campero y de Santiago Vaca Guzmán, La Isla y quizás alguna otra), la producción de novelas y leyendas bolivianas decimonónicas (así como la de muchos otros géneros), al no existir muchas re-ediciones, sigue siendo en gran medida desconocida. A esta observación se puede añadir que, en Bolivia, a diferencia de muchos otros países latinoamericanos, se cuenta con poquísimas ediciones modernas de los periódicos del siglo XIX (sean facsimilares, digitales o en microfilme). En este contexto, destaco sobre todo dos grandes méritos de Ficcionalización de Bolivia: primero, rescatar del olvido muchas obras y presentar el corpus casi completo (porque siempre hay exclusiones y olvidos involuntarios, y porque seguramente surgirán hallazgos de otras obras perdidas en el futuro...) de novelas/leyendas del período; y segundo, recordar que el medio de publicación de la mayoría de los relatos fue la prensa.

En este último aspecto, queda claro que estas obras, aunque algunas estén olvidadas en el presente, tuvieron una difusión relativamente amplia cuando se publicaron. Los periódicos y revistas tenían de 200 a 500 o más subscriptores, y circulaban "de mano en mano," y "por todo el vecindario," según observadores de la época, en ciudades con no más de 20 o 40 mil pobladores; es decir, los periódicos tenían un tiraje nada despreciable y contaban con una importante circulación informal, la de sus folletines sobre todo. Como triste evidencia del interés por la literatura serial, se puede constatar que a más de un periódico en los archivos le falta la sección del folletín (cortada, seguramente, por alguien que coleccionaba, número tras número, estos relatos seriales). Al mismo tiempo, al publicarse muchas obras en las páginas de los periódicos, participan de otras formas de leer, distintas a la cómoda lectura de un libro, que las conectan con las redes textuales y discursivas de la prensa. Los relatos que salen en la prensa comparten espacios y dialogan con una serie de textos y discursos periodísticos afines, entre los que se pueden destacar proyectos pedagógicos nacionalistas; notas editoriales que definen o reproducen ideologías compartidas; textos sobre celebraciones patrias y sobre héroes e historias nacionales; textos de viajeros, exploradores y naturalistas, y otros semejantes preocupados por la descripción del territorio nacional y sus contenidos; y textos con otros tipos de literatura con los que también dialogan, sean obras de autores extranjeros o bolivianos. En su "Introducción" y en las notas editoriales, Soto acierta al ilustrar muchas de estas relaciones intertextuales. A modo de ilustración, 
podríamos mencionar el caso de Bartolomé Mitre cuando en Soledad (1847), la primera obra incluida en Ficcionalización, cita dos versos de "un joven poeta boliviano". En una nota, se aclara lo siguiente: "El título del poema es "Una impresión al pie del Illimani", del poeta romántico Mariano Ramallo, que fue publicado en La Época el 23 de agosto de 1845 y posteriormente en La Abeja Paceña el 16 de julio de 1846" (I, 78).

En síntesis, las novelas/leyendas publicadas en Ficcionalización de Bolivia, en estrecha relación con los otros textos literarios y la variedad de discursos que se publican en las páginas de los periódicos, fueron constituyendo a lo largo del siglo una literatura nacional boliviana, concepto que si bien entendemos en principio (a partir de unas escasas novelas, alguna obra de teatro y los libros de pocos poetas), desconocemos en sus muchos y complejos detalles. Ficcionalización revela que este desconocimiento es tan grande, que el objeto mismo de lo que es la literatura boliviana del siglo XIX debe ser re-visitado. Al mismo tiempo, la monumental obra de Juan Pablo Soto, con la colaboración de Máximo Pacheco, empieza a remediar este desconocimiento al rescatar obras olvidadas y re-contextualizar las pocas conocidas. A partir de esta publicación y otras semejantes, y de los estudios críticos que vayan generando, se irá reformulando lo que se entendía como parte importante de los orígenes de nuestra literatura.

Fernando Unzueta

The Ohio State University

\section{(cc) BY}

\section{This journal is published by the University Library System of the} ULS D-Serle University of Pittsburgh as part of its D-Scribe Digital Publishing Program, and is cosponsored by the University of Pittsburgh Press. 